\title{
Green economics as a tool for prioritising brownfield rehabilitation in Greece
}

\author{
D. Kaliampakos, D. Damigos \& T. Karachaliou \\ Laboratory of Mining and Environmental Technology, \\ School of Mining Engineering and Metallurgy, \\ National Technical University of Athens, Greece
}

\begin{abstract}
Given the limited resources, an effective way of prioritizing brownfield rehabilitation could be according to the total costs and benefits produced by each site. Aside from the potential return from a profitable new use, brownfield rehabilitation benefits also come from contamination and stigma elimination. The latter, however, are not directly incorporated in the market, and therefore a comparable value is missing. Environmental valuation methods could monetize environmental enhancement in order to attain the comparison of benefits with remediation costs, on the same basis. Towards this direction, an interactive tool is currently being developed, namely the Greek Environmental Valuation Database (GEVAD), on the grounds of the benefit transfer method. This tool can facilitate the valuation of brownfield external costs and benefits, improving the justification of rehabilitation funds.
\end{abstract}

Keywords: brownfield, Greece, case studies, environmental economics, cost benefit analysis, benefit transfer.

\section{Introduction}

Over the past decades, almost all of the developed countries have restructured their traditional heavy manufacturing industries, causing older sites to be abandoned. This is the result of stricter environmental regulations, changing markets and innovative production technology. In turn, communities have experienced downsizings, shutdowns and relocations, leaving underused or vacant industrial properties behind. Considerable effort has been made, in the USA and in many European Countries, to understand the nature of the problem 
and provide tools to resolve it. Greece has to face, too, the environmental and socioeconomic implications caused by brownfield land. Until now, though, there is no evidence of systematic, concerted actions towards brownfield redevelopment. This may be due to the fact that there is no strong public awareness of the situation, while the Greek government does not support adequately the voluntary initiatives with financial incentives.

According to a recent study of the Laboratory of Mining and Environmental Technology of the National Technical University of Athens [1], the list of some notable brownfield sites that have been recorded in Athens includes Factory "Fix", Gasworks "Gazi", French Lavrio Mines Company, Silk-mill "Athinais", Factory "Thermis", Factory "Phoivos", Former National Printing Office, Public Tobacco Factory, Steam Power Station of Neo Faliro, Factory-Engine Room of OSE, Printing Office "Empros", Greek Company of Chemical Products and Fertilizers, etc.

The number of abandoned or underused industrial sites, posing threats to human health and the environment, is quite big and is still increasing, yet many of them offer the grounds for affordable remediation, if needed, and further redevelopment. The cases described below, are indicative of their significant potential, even when the conditions seem initially unfavorable.

\section{Brownfields in Athens - success stories}

\subsection{Lavrio Technological and Cultural Park}

Lavrio Technological and Cultural Park is one of the most important projects related to brownfield regeneration in Greece. It is located within the metropolitan area of Athens, on the north side of the city of Lavrio. The site holds a significant mining past dating back to ancient times, while in the recent history accommodated the French Lavrio Mines Company, the most significant industry at the time. The mining company was established by J. B. Serpieri, in 1875, in order to exploit the ancient slags and extract the silver-containing lead ores and was responsible for the foundation of a 10,000 residents' company-town and multiple technological innovations.

In 1990 deindustrialisation trends in specific areas in Greece forced the industrial facility to shut down its units. The remains were buildings of great architectural and aesthetical value. The environmental site assessment, however, showed the presence of many heavy metals in the soil, which was characterized as unusually heavy contaminated. In order to deal with the contamination and, at the same time, provide for a feasible activity, the National Technical University of Athens undertook the redevelopment of the old French Mine Company complex as a Cultural and Technological Park. The remediation plan for the site includes excavation, transfer and disposal of the contaminated land and construction of an underground space used as a hazardous waste storage facility. After having partially restored the site and ensuring that the risk to human health has been eliminated, the Park started to operate [2]. To date, fifteen buildings have been restored, some of which are already leased, whereas the rest of them 
are intended to accommodate administrative and cultural services. The restoration of the buildings was guided by an attempt to turn into account their original functionality, maintaining their industrial character.

\subsection{Former factory "Gazi" - "Technopolis"}

The former gasworks factory, known as "Gazi", was established in 1857, under the directorship of a French company in order to illuminate the city of Athens. It was when the industrial revolution was just starting to make its appearance within the newly founded Greek State. The siting of the industrial complex was based upon its central position. The development of the surroundings, later on, conduced to the recognition of the area as one of the most significant industrial places until nowadays. In 1887, the need for town gas expanded. In addition to lighting the streets, homes and industries were added to the list of gas consumers. During the years 1920-1952 German technology was introduced to improve the quality of gas. The last phase of operation (1952-1984) marked the gasworks decay. In the 1960s, the gasworks did not function at full capacity, as the specific form of energy was considered 'outdated'. In 1983 the gas production process from coal was suspended. Gasworks operation was considered anachronistic, raising intense reactions from the public, not only due to its environmental burden, but also due to its vital location in the city core, near Acropolis. Thus, in 1984, the factory's function was ceased.

Today, the site has been redeveloped as a cultural, modern multipurpose center, known as "Technopolis". The rehabilitation of the buildings was attained, abiding by two basic principles: conservation of the industrial past authenticity along with functionality. The result consists of a living Industrial Archeology and Architecture Museum, with the ability to host important events of science and the arts.

\subsection{Former silk-mill "Athinais"}

Silk-mill "Athinais" was established in 1920, in a location facing the Acropolis, near the Ancient Agora of Athens and operated for two decades, producing natural silk of the finest quality. It was recognised as one of the city's modernage landmarks. During World War II, the factory suspended operation to become an air-raid shelter. Following the city's liberation, "Athinais" started running again, but had to face post-war technological advancements, which had begun to revolutionize the industry. Finally, in the mid 50's, unable to march with the times and compete with rayon, which gradually replaced natural silk, the old factory ceased operation and was merely used as a storage facility. Today, the $6,500 \mathrm{~m}^{2}$ old silk factory has been converted into a modern multi-purpose centre that hosts a wide range of business initiatives and cultural activities, such as conferences, business meetings and exhibitions. The renovation project was designed in a way to preserve the building's industrial character and accentuate its distinctive architectural features. 


\section{Reconsidering brownfield prioritization}

Despite the existing potential, there are many obstacles opposing to brownfield redevelopment. The most important one is the lack of the necessary resources to restore all the sites, meaning that, inevitably, a choice is required. In USA, each recorded brownfield is classified in the National Priorities List, which is intended to determine which sites warrant immediate investigation and possibly remediation. The ranking of the hazardous sites is founded on a screening tool, called the Hazard Ranking System (HRS), which assigns numerical values to factors related to human health and ecological risk, depending on the site's conditions. As far as Greece is concerned, the decision-making seems to be mostly guided by the site's history and location, its special industrial architecture and some personal memories and feelings rather than a systematic method focused on the optimization of the restoration funds or the elimination of the environmental burdens.

Brownfield evaluation, based on risk assessment methodology is justified by the fact that these sites may be related to adverse environmental impacts. And for that it is a sound first step. However, this method is inadequate, in cases where the environmental problems are alike but the consequences differ, depending on the number of people or species that are affected. In that case, while the cost remains the same, there is a difference in the social benefits deriving from remediation, which cannot be estimated through the risk assessment approach. Thus, in order to optimize the allocation of the available funds, the remediation and redevelopment benefits gained should be quantified and compared to the costs required.

Nowadays, there is an extensive literature indicating that contaminated sites are affected from the so-called stigma-related damages. Stigma generally refers to the loss in value of a property that has suffered some type of contamination. This loss is not attributed to remediation costs but on perceived risks associated with the contamination. In many situations, it is documented that stigma extends beyond the boundaries of the site, reducing the value of nearby residential, as well as commercial and industrial properties, at least temporarily. In general, it is well established that value reduction is associated with the distance from the contaminated site. For example, Reichert [3] found that properties within a distance of $700 \mathrm{~m}$ from an Ohio Superfund toxic waste site lost approximately $15 \%$ of their value, while losses were negligible $2 \mathrm{~km}$ away from the site. Cumulative losses attributed to this hazardous site were nearly 11 million USD (1994). The Office of Emergency and Remedial Response [4] found that the cumulative property value loss from 1,213 hazardous sites amounted to approximately 750 million USD (1996) at the one-mile threshold, and 2.1 billion USD (1996) at the two-mile threshold. Although in 1997, the OERR dismissed the results of the previous study [5], it was suggested that price effects range from 2 to $8 \%$ of the original property value within a range up to 3 to 7 miles. Similar results are reported from several studies [e.g. 6-9]. 
The following section outlines some fundamental definitions and principles of environmental economics, along with the basic techniques, in order to provide the theoretical and practical background of environmental valuation.

\section{Environmental valuation}

Although environmental assets are valuable to the society, there is no market mechanism assigning prices to environmental goods and services. In order to incorporate cost - benefit analysis in the decision making process, as in the case of brownfields, it is necessary to provide a common measure of comparison between benefits and costs, using monetary values. Environmental valuation is attained by estimating the effect of a change in environmental conditions on social welfare, which is called the total economic value (TEV) of the change. Practically, this is based on people's willingness to pay (WTP) an amount of money in order to avoid an environmental degradation or their willingness to accept (WTA) a compensation in order to suffer the environmental impacts incurred [10-13]. TEV can be divided into use values and non-use values reflecting the fact that people also value resources for moral reasons and bequest reasons, unrelated to current or future personal use of the good.

There are two kinds of original environmental valuation techniques: the revealed preference methods that estimate the people's actual behavior and the stated preference techniques that estimate the intended behavior. Revealed preference methods include Travel Cost Method (TCM), which is mainly used to measure the demand for recreational activities through time and travel cost expenses to access a site and Hedonic Pricing Method (HPM), which is used to estimate the economic value of environmental assets that directly affect market prices, such as air and water pollution, noise, proximity to recreational sites etc. HPM is usually used to measure variations in the house market, reflecting the value of the local environmental quality. Finally, Contingent Valuation (CVM) is referred as a stated preference method, because it is an experimental technique that directly asks people what they would be willing to pay or to accept in a hypothetical situation, instead of inferring values of actual choices. However CVM is the most popular method because it can estimate the total economic value, both use and non-use. CVM has been in use for over 35 years and there are more than 2,000 studies dealing with the topic [14].

Despite their recommended use, original environmental valuation methods are a long lasting and costly procedure, while there is usually limited time and resources. As a result, a method based on secondary data, known as Benefit Transfer Method (BTM), is often applied. BTM makes use of the results of one or more primary studies to infer the values for the environmental impacts or benefits for the site of concern. The site of the previous research is usually called the "study site" while the site to which the benefit estimate is transferred is called the "policy site". BTM is a useful alternative when original research is not possible or there is no need for high accuracy. The method has been criticized for not producing reliable values, thus, in most of the cases the inaccurateness is due to the imprecision and the deficiency of the original study, the difference in the 
research and statistical methods applied or the instability of data over time. In order to reduce the margin of error of a benefit transfer application, several conditions should be met $[15,16]$. Studies transferred must be based on adequate data, sound economic method, and correct empirical technique [17]. The study site and the primary policy site should exhibit similar environmental resource and change in the quality (or quantity), similar markets for the sites, unless there is enough usable information provided by the study on own and substitute prices, similarity of demographic characteristics between the two populations and their cultural aspects and similar extent and magnitude of the population that will be affected by the expected site or resource impacts.

There are two benefit transfer techniques: (a) value transfer and (b) function transfer. Value transfers consist in the transfer of a single estimate from a study site, or a measure of central tendency of the estimates from several study sites. Function transfers consist in the transfer of a benefit or demand function from a study site that is then adopted to fit the special elements of the policy site [e.g. 16]. When transferring values, spatial and temporal adjustments should be made, regarding differences of income, price level and time.

\section{Greek Environmental Valuation Database (GEVAD)}

Reaching a satisfactory degree of reliability in benefit transfer application requires having access to a large range of original studies in order to find the most appropriate ones, which have similar characteristics with the study site. So far, two tools are well known and widely used: the EVRI (Environmental Valuation Reference Inventory) and the ENVALUE databases. EVRI is a webbased database that was developed by Environment Canada in collaboration with a number of experts and organizations. ENVALUE was constructed by New South Wales Environment Protection Authority (NSW EPA) and was last updated in October 1998. These two tools can be searched by environmental attribute valued, valuation technique used, location etc, so as to identify the most relevant primary studies. Despite the fact that EVRI and ENVALUE are globally accessed for retrieving field valuation studies, they both have weaknesses as far as applications in Europe are concerned. According to Navrud and Vågnes [18], only 56 out of the more than 650 European Valuation studies were recorded in EVRI, which corresponds to less than $10 \%$.

The European Union's motivation towards sustainable development and the increasing need to include environmental valuation in the decision-making processes emerged the necessity to develop a similar tool focused mainly on recent European studies. A relative project, which is co-funded by the European Social Fund and Greek National Resources, is being carried out by the Laboratory of Mining and Environmental Technology of the National Technical University of Athens.

More specific, the scope of the appointed project is the development of a user-friendly, interactive "environmental valuation" tool, in compliance with the institutional and research context of the international scientific community. The tool will provide the necessary data to value environmental impacts of industrial 
activities in Greece, as well as in other European countries, based on the BTM. The prescribed actions of this project include literature review of a large number of studies, codification and adjustment to the particular characteristics of European space using suitable techniques and development of a web-based software to guide the users. The GEVAD tool (Greek Environmental Valuation Database) is intended to be completed till the end of 2006. By that time, approximately 400 studies will have been registered. To date, 1200 studies have been tracked and 1017 from them are selected to be reviewed in the next phase, focusing on the ones that are spatially and temporally more relevant to Greece and Europe, in general.

Indicatory of the emphasis given on the most recent research is the fact that $42.9 \%$ of the studies selected were conducted in the last five years and almost $75 \%$ in the last ten years. Table 1 lists the classification of the studies according to their date.

Table 1: $\quad$ Studies classification according to their date.

\begin{tabular}{|c|c|}
\hline Year & Portion \% \\
\hline $1970-1974$ & $0.4 \%$ \\
\hline $1975-1979$ & $2.0 \%$ \\
\hline $1980-1984$ & $4.5 \%$ \\
\hline $1985-1989$ & $5.0 \%$ \\
\hline $1990-1994$ & $14.2 \%$ \\
\hline $1995-1999$ & $31.0 \%$ \\
\hline $2000-2005$ & $42.9 \%$ \\
\hline
\end{tabular}

Additionally, 57.0\% of the recorded studies concern Europe, filling the gaps of the databases mentioned (Figure 1).

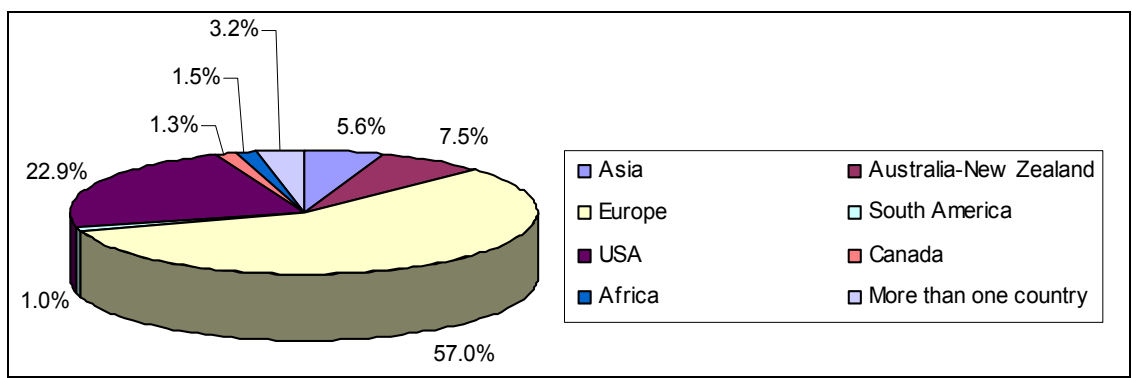

Figure 1: $\quad$ Studies classification according to geographical area.

Studies are classified in GEVAD according to the environmental asset, good or service, which is valued. Amenity, water and air contamination along with landscape degradation seems to be the most interesting attributes to be estimated in monetary terms (Figure 2). 


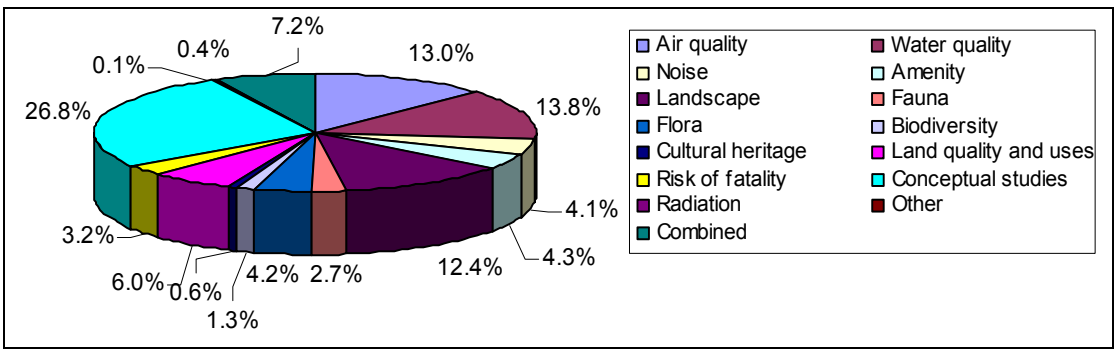

Figure 2: Studies classification according to the environmental asset that is valued.

\section{Conclusions}

Brownfield regeneration is an established trend in the modern world. However, the lack of the necessary funds for dealing totally with the problem, calls for a clear and sound way for prioritizing the various cases, in terms of emergency and net social benefits gained.

So far, prioritization of these sites is accomplished by means of risk assessment techniques. Nevertheless, brownfield redevelopment is, first of all, an economic puzzle. Towards this direction, the application of environmental valuation methods could be beneficial, in order to come up with more fair choices. The monetization of environmental costs and benefits reveals hidden economic aspects and provides the means to evaluate a redevelopment project not only according to its financial profitability but also on its performance towards sustainable development.

Although primary studies are always the "first-best" option, Benefit Transfer Method is well recognized as a cost-effective alternative, when original study of the problem is not possible due to budget constrains or time limitations. In any case, values should be transferred cautiously, taking into account that the results are affected by several parameters (e.g. socioeconomic characteristics of the "policy" and "study" sites, stability of data over time, since the primary studies occurred at different points in time, etc.).

GEVAD, which stands for "Greek Environmental Valuation Database", aims at expanding the coverage provided by the widely used EVRI and ENVALUE databases to recent EU valuation studies. In this way, it creates a suitable pool of data that will encourage the application of benefit transfer in Greece and other European countries. This attempt will further facilitate the valuation of external costs and benefits of several types of projects and activities, including brownfield. Hence, it can be used as a tool for the prioritization of the hazardous sites, on an economic basis, in order to appease the burdens involved in decisionmaking processes. 


\section{Acknowledgements}

The GEVAD Project is co-funded by the European Social Fund (75\%) and National Resources (25\%) - Operational Programme for Educational and Vocational Training (EPEAEK II)- PYTHAGORAS.

\section{References}

[1] Kavallari E. Old industrial areas (brownfields) redevelopment- the case of Attica, dissertation, NTUA, 2005.

[2] Karachaliou T., Kaliampakos D., Redeveloping derelict urban space, the case study of Lavrio, Greece, proceedings of the International Conference on Managing Urban Land, CABERNET 2005.

[3] Reichert, Alan K. Impact of a Toxic Waste Superfund Site on Property Values. Appraisal Journal, 65, 4, pp. 381-92, 1997.

[4] Office of Emergency and Remedial Response. Estimating Property Value Impacts From Superfund Site Cleanup, 1996.

[5] Office of Emergency and Remedial Response. Plan for Socioeconomic Analysis, Working Draft, 1997.

[6] Thayer, M., Albers, H., Rahmatian, M. The benefits of reducing exposure to waste disposal sites: a hedonic housing value approach, J. Real Estate Res., 7, 265-282, 1992.

[7] Elliot-Jones, M. Stigma in light of recent cases, Nat. Res. Enviro. 56-59, 1996.

[8] Farber, S. Undesirable facilities and property values: a summary of empirical studies, Ecol. Econom. 24, 1-14, 1998.

[9] McCluskey, J.J. and Rausser, G.C. Estimation of perceived risk and its effect on property values, Land Econom. 77, 42-55, 2001.

[10] Pearce, D. and Turner, R.K. Economics of natural resources and the environment. Harvester Wheatsheaf, Hertfordshire, U.K., 1990.

[11] Johansson, P-V. Cost-Benefit Analysis of Environmental Change. Cambridge University Press, Cambridge, 1993.

[12] Turner, R.K., Pearce, D. and Bateman I. Environmental economics: An elementary introduction. Harvester Wheatsheaf, Hertfordshire, U.K., 1994.

[13] Kula, E. Economics of Natural Resources, the Environment and Policies. Chapman and Hall, London, U.K., 1994.

[14] Carson, R.T., Wright, J., Alberini, A., Carson N., Flores, N. A Bibliography of Contingent Valuation Studies and Papers. Natural Resource Damage Assessment, Inc., La Jolla, January, 1995.

[15] Desvousges, W.H., Naughton, M.C., Parsons, G.R. Benefit transfer: Conceptual problems in estimating water quality benefits using existing studies. Water Resources Research. 28(3):675-683, 1992.

[16] Rosenberger, R.S. Loomis, J.B. Benefit transfer of outdoor recreation use values: A technical document supporting the Forest Service Strategic Plan, (2000 revision). Gen. Tech. Rep. RMRS-GTR-72. Fort Collins, CO: 
U.S. Department of Agriculture, Forest Service, Rocky Mountain Research Station, 2001.

[17] Freeman, M., III. On the tactics of benefit estimation under Executive Order 12291. In: Smith, V. Kerry, ed. Environmental policy under Reagan's Executive Order: The role of benefit-cost analysis. Chapel Hill, NC: The University of North Carolina Press, chapter 6, 1984.

[18] Navrud, S. and Vågnes, M. Assessment of Environmental Valuation Reference Inventory (EVRI) and the Expansion of Its Coverage to the EU, 2000, http://europa.eu.int/comm/environment/enveco/studies2.htm\#24 